\title{
Seroprevalence of Hepatitis B Virus in Multitransfused Patients with Special Reference to Occult Hepatitis B Virus Infection
}

\author{
M. Paranjpe Supriya ${ }^{1}$, S. Supare Sundaram ${ }^{2}$, Nataraj Gita ${ }^{1}$ and R. Mehta Preeti ${ }^{1}$ \\ ${ }^{1}$ Department of Microbiology, KEMH, Parel Mumbai, India \\ ${ }^{2}$ Department of Microbiology, GMC, Nagpur, India \\ *Corresponding author
}

\section{A B S T R A C T}

\begin{tabular}{|l|}
\hline Ke y w o r d s \\
$\begin{array}{l}\text { Hepatitis B virus, } \\
\text { Seroprevalence, } \\
\text { Multitransfused } \\
\text { patients }\end{array}$ \\
\hline Article Info \\
\hline $\begin{array}{l}\text { Accepted: } \\
\text { 20 June 2019 } \\
\text { Available Online: } \\
\text { 10 July } 2019\end{array}$ \\
\hline
\end{tabular}

Keywords

Hepatitis B virus,

Seroprevalence,

Multitransfuse

Accepted:

10 July 2019
Hepatitis B virus (HBV) is one of the most important agent causing transfusion transmitted infections in multitranfused patients. HBV-DNA is a concern for transmission from transfusion or transplantation in serologically negative blood for HBV i.e., occult hepatitis B (OHB). The aim of this study is to find out the prevalence of $\mathrm{HBV}$ infection in multitransfusd patients including OHB infections. The present study was conducted in 200 multitransfused patients attending the haematology/thalassemia OPD. Blood sample were collected and tested for HBsAg, Anti HBs, Anti HBc and HBV DNA by DNA PCR. Out of the total 200 patients, total prevalence of $\mathrm{HBV}$ amounted to $28 \%$ including various markers of HBV infection was HBsAg only 3(1.5\%), Anti HBc only 49(24.5\%) and Anti HBc plus HBs Ag 4(2\%). Out of 49 AntiHBc positive samples 3(6.12\%) patients were positive for HBV DNA. Newer methods such as HBV DNA PCR, Anti HBc should be introduced in the routine screening of blood donors to reduce the window period and to prevent transmission. Emphasis on complete hepatitis B vaccination and regular follow up for anti HBs titre, providing booster doses for those in need should be implemented.

\section{Introduction}

In recent years, there has been increased public concern about the safety of blood transfusion with respect to transfusiontransmitted infections. Though regular blood transfusion improves the overall survival of patients and in spite of routine screening of blood or blood products it carries a definite risk of infection with blood-borne virus (1) such as hepatitis B virus. (2) Blood units are screened with assays of steadily increasing sensitivity due to availability of Hepatitis B surface antigen (HBsAg) since 1971(3).

The serological diagnosis of hepatitis B virus (HBV) infection is mainly based on hepatitis B surface antigen (HBsAg) detection assays, and the absence of HBsAg is believed to exclude infectivity. However, presence of HBV DNA in circulation/liver without detectable HBsAg, with or without the 
presence of any other HBV antibodies, is defined as occult HBV infection (OBI) (4).

HBV-DNA without HBsAg is a concern for transmission from transfusion or transplantation. Patients from countries highly endemic for HBV are more likely to develop occult HBV infections.(5) Occult HBV may impact in several different clinical contexts, including the transmission of the infection by blood transfusion or organ transplantation and its acute reactivation when an immunosuppressive status occurs.(6) Carriers of occult HBV infection may be a source of HBV transmission in the case of blood transfusion.(7) Another important clinical manifestation of HBV occult infection is its reactivation during immunosuppression. (8) The present study was designed to determine seroprevalence of $\mathrm{HBV}$ in multitransfused patients in our setting.

\section{Materials and Methods}

The present study was conducted in a Seth GS medical college and KEMH, Parel Mumbai after obtaining institutional ethics committee permission. The study was conducted on 200 Multitransfused patients visiting haematology/thalassemia OPD who had received more than two units of blood transfusion and their last blood transfusion was at least three months prior to their enrolment in the study. After obtaining clinical data, including age, number and duration of transfusions received, and history of HBV vaccination, were collected from the patients as per the case record form. $5 \mathrm{ml}$ of venous sample was collected from each patient in a plain vacutainer prior to the transfusion. Serum was separated in two sterile vials and stored at $-20^{\circ} \mathrm{C}$ until all the samples were tested. ELISA was performed for detecting Hepatitis B surface antigen (HBsAg) and Anti $\mathrm{HBc}$, and Anti $\mathrm{HBs}$ from one tube and the samples which were Anti
$\mathrm{HBc}$ positive further tested for HBV DNA PCR from another vials

HBVDNA was extracted from $200 \mu \mathrm{L}$ of serum by using QIAamp DNA blood Mini Kit presence of HBV DNA was detected by sensitive nested PCR amplification of HBV. Precautions were taken during amplification process to protect against carry over contamination and false positive HBV DNA on PCR [9]. In addition, each sample was tested in duplicates, and negative controls were included during each assay. The data were analyzed as proportions. Statistical significance of the results was evaluated by using the chi-square test/Fisher's exact test. A $P$ value of $<0.05$ was considered as significant.

\section{Results and Discussion}

The study enrolled 200 multitransfused patients. Male were predominant $113(56.5 \%)$ as compared to females $87(43.5 \%)$. The patient's age ranged from 4-64 years with a mean age of 21.32years $( \pm 10.9)$. Majority of the patients $134(67 \%)$ were from thalassemic group. The number of blood transfusions received by each patient ranged from 4 to 600 with a mean of $235.89( \pm 243.0)$ (Fig. 1). $162(81 \%)$ patients had received vaccination against $\mathrm{HBV}$.

Out of the total 200 patients, the total prevalence of $\mathrm{HBV}$ amounted to $28 \%$

The positivity for various markers of Hepatitis $\mathrm{B}$ infection was HBsAg only $3(1.5 \%)$, Anti HBc only $49(24.5 \%)$ \& Anti HBc plus HBs Ag 4(2\%) amounting to a total seropositivity of $28 \%$ (Fig. 2).

In the present study, 162(81\%) multitansfused patients were vaccinated, 25(12.5\%) patients were unvaccinated and $13(6.5 \%)$ patients were with incomplete vaccination. 
Of the unvaccinated patients, $19(76 \%)$ were infected with $\mathrm{HBV}$ as compared to $33(20.37 \%)$ amongst vaccinated patients and $4(30.76 \%)$ of incompletely vaccinated patients. This suggests that there is a association between vaccination and absence of HBV infection $(\mathrm{P}<0.001)$

With the advent of improved technology and universal screening of blood, the risk of transmission is now decreased but it is definitely present. (1) Although Government of India has made it mandatory to screen donated blood for HBV (1971), it is continue to be a problem in multitransfused patients in India.(10)

The majority of the patients in the study were thalssemic (11) The general incidence of thalassemia in India varies between 3 and $17 \%$.(12) It is estimated that there are about 65,000-67,000 beta-thalassemia patients in India with around 9,000-10,000 cases being added every year.(13) This may explain the greater number of thalassaemia patients being enrolled in the present study

In the present study, the prevalence of HBV of $28 \%$. Laguna-Torres VA et al., have shown a similar high prevalence of HBV (45.8\%) (2)

In the present study, HBV infection was detected by using two markers HBsAg and Anti $\mathrm{HBc}$. Anti $\mathrm{HBc}$ was the most common HBV marker detected (24.5\%) as compared to HBsAg (3.5\%) (Fig. 2). Similar finding of high seropositivity for Hepatitis B infection is reported by laguna et al.,(45.8\%), Singh et al., (25.7\%), Sabat et al., (22.3\%) [2, 4, 14] as they also have taken both HBsAg as well as Anti $\mathrm{HBc}$ seropositivity for calculating the seroprevalence.

Other studies Shah et al., 2\%, Bhavsar et al., 6\%, Soni, 1.47\%, Twisha Oza et al., $0.52 \%$ $(13,15,16,17)$ have reported a lower rate of
$\mathrm{HBV}$, as they have considered HBsAg as the only marker for Hepatitis and have not tested for anti HBc. This difference may be explained based on the immunological response to $\mathrm{HBV}$ infection. HBsAg typically appears early at the end of the first month and in most patients disappear by six month, whereas Anti $\mathrm{HBc}$ appears 1-2month after HBsAg and remains lifelong.

The rate of HBsAg (3.5\%) is comparable with the general population (2-8\%) and voluntary blood donors (1-4\%) (18)

The reason for the high rate of HBV infection in the present study could be manifold. The mandatory screening for HBV started in 1971. So it is possible is that the patients especially in the older age group would have contracted transfusion transmitted HBV infection because of the transfusions prior to the screening program.

According to the $\mathrm{WHO}$ report on prevention of $\mathrm{HBV}$ in India, HBsAg prevalence among general population ranges from $0.1 \%$ to $11.7 \%$ being between $2 \%$ to $8 \%$ in most studies(19) placing India in intermediate zone.

Considering, on an average, HBsAg carrier rate of $5 \%$, the total number of HBV carriers in the country was estimated to be about 50 million that forms nearly $15 \%$ of the entire pool of HBV carriers in the world and is the second largest pool of chronic HBV infections in the world. (20) As the blood units would be sourced from this large pool of HBV infection, the prevalence of $\mathrm{HBV}$ is expected to be more. Seroprevalence of HBsAg in blood donors was reported in a range of $1.38 \%$ to $5 \%$.(4) Also the frequency of HBsAg in blood donors is more than other infectious diseases because of asymptomatic carriers and chronic liver disease. $(11,21)$ The greatest threat to the safety of the blood supply is the donation of blood by seronegative donors during the 
infectious window period when the donors are undergoing seroconversion (22) The screening programme for blood donors in India detects HBsAg only and not core antibodies or HBV DNA so there is a possibility of missing the infection in window period as well as during occult infection which might result in the transfusion of infected blood. The sensitivity of $\mathrm{HBsAg}$ screening assays has enormously improved over time reaching $0.1 \mathrm{U} / \mathrm{ml}$ but remains unable to detect the preseroconversion window period or samples with very low viral load after decades of chronicity or clinical recovery. (23)

El Zayadi et al., (24) called for implementing the anti $\mathrm{HBc}$ test as a routine assay, which would certainly eliminate possible HBV infected blood units as rejection of these units would be beneficial to decrease the risk of HBV transmission.

The rate of $\mathrm{HBV}$ infection of $76 \%$ (16\% HBsAg and $60 \%$ anti $\mathrm{HBc}$ ) in the unvaccinated patients is high as compared to $20.37 \%(1.85 \%$ HBsAg and $18.51 \%$ Anti $\mathrm{HBc}$ ) in the vaccinated group of patients which highlights the protective role of vaccine $(\mathrm{P}<0.001)$ (Fig. 3).
In the present study, out of the 162 completely vaccinated patients, 144 (88.88\%) were protected as they had antibody titres of $\geq 10$ $\mathrm{mIU} / \mathrm{ml}$ (Fig. 4). Out of these, two patients $(1.38 \%)$ were $\mathrm{HBsAg}$ positive and 26 $(18.05 \%)$ were Anti $\mathrm{HBc}$ positive indicating a HBV infection of $19.44 \%$. As a significant number $(80.56 \%)$ were not infected, vaccination again proved to be an effective tool for protection against HBV infection.

The two patients despite of the anti HBs had HBsAg positivity this could be due to the result of viruses harbouring pre core or surface gene mutations in a region critical for antibody reactivity to the virus (2)

Coleman $\operatorname{PF}(25)$ in their study on hepatitis B surface antigen have reported that substitutions at positions outside of the "a" determinant appear to be readily detected by current commercially available HBsAg immunoassays and these mutant viruses propagate in the presence of a neutralizing immune response (25)

The presence of anti $\mathrm{HBc}(18.05 \%)$ of the vaccinated patients could be because of the natural resolved infection.

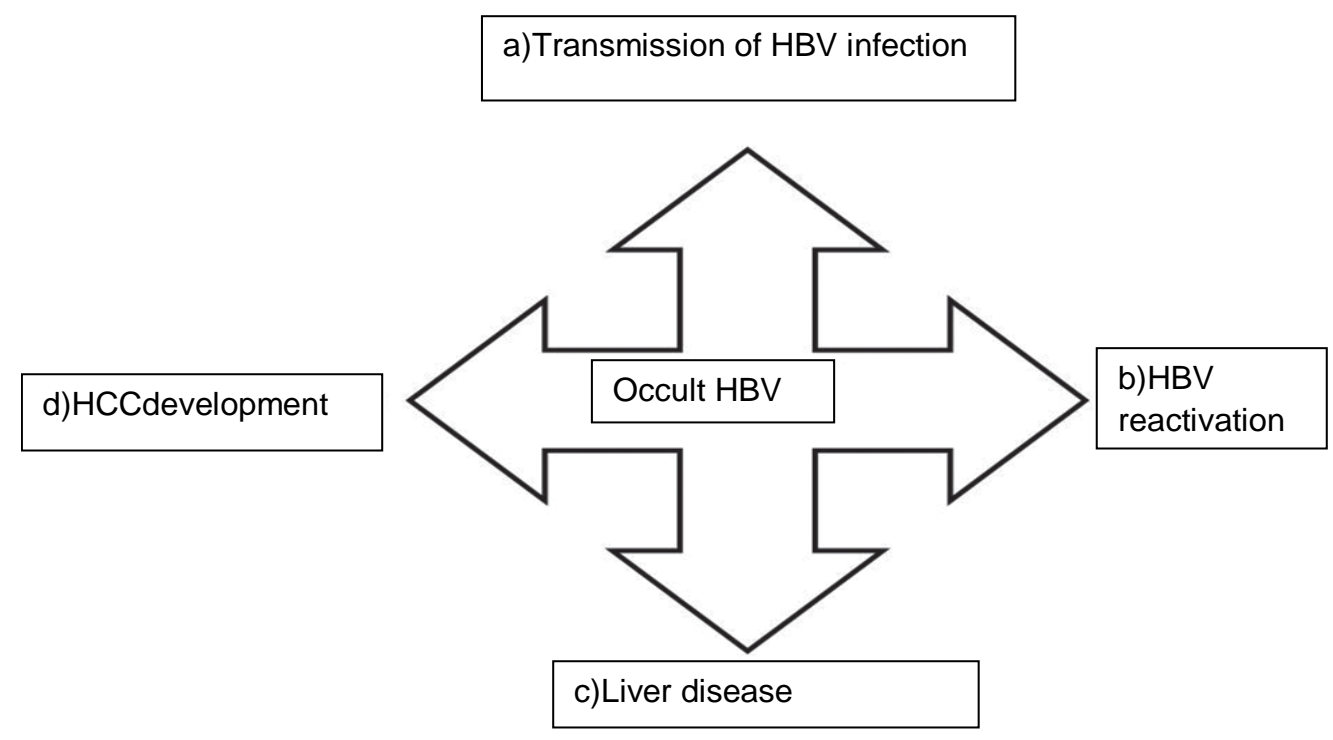


Fig.1 Study Cohort

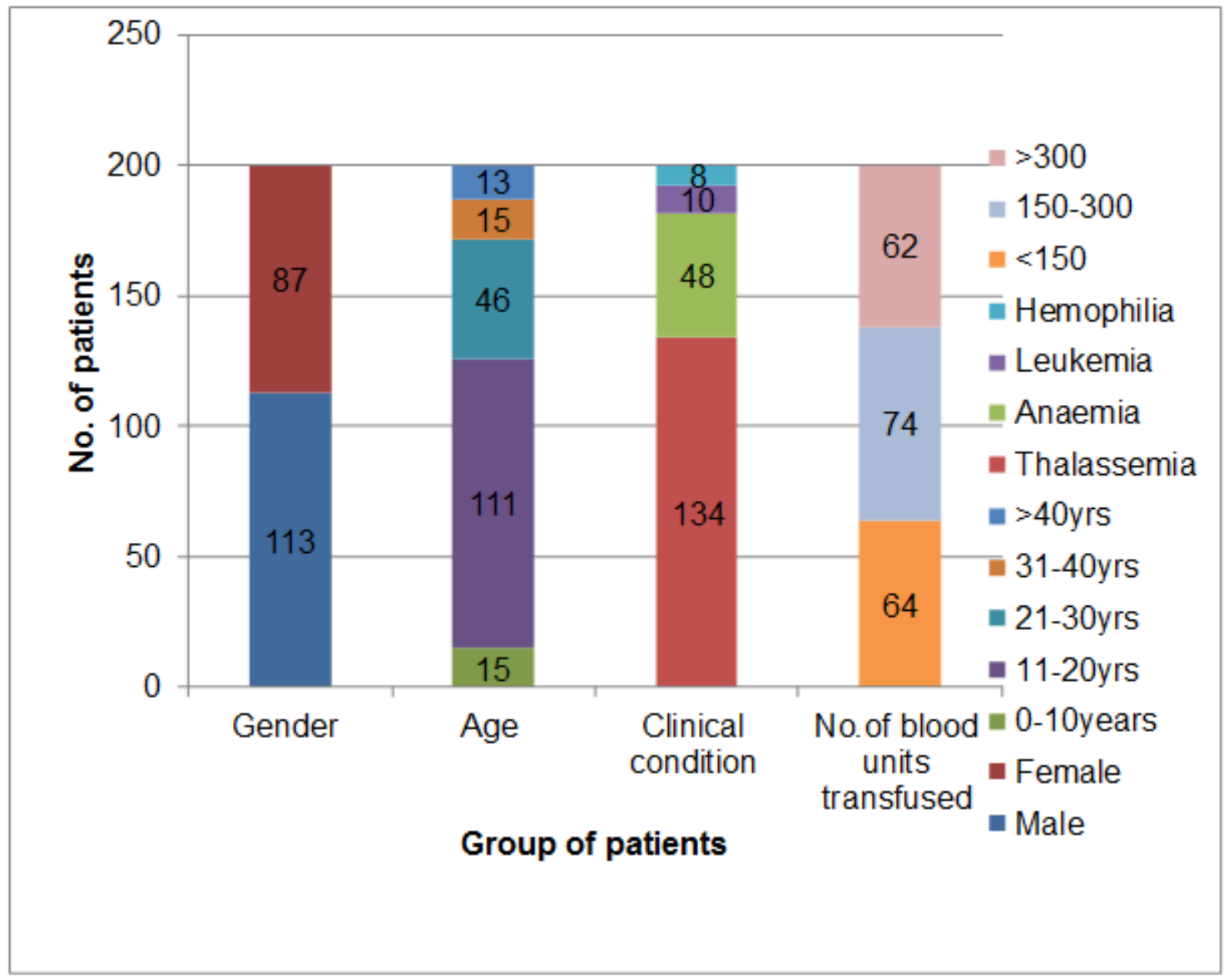

Fig.2 Seropositivity of HBV

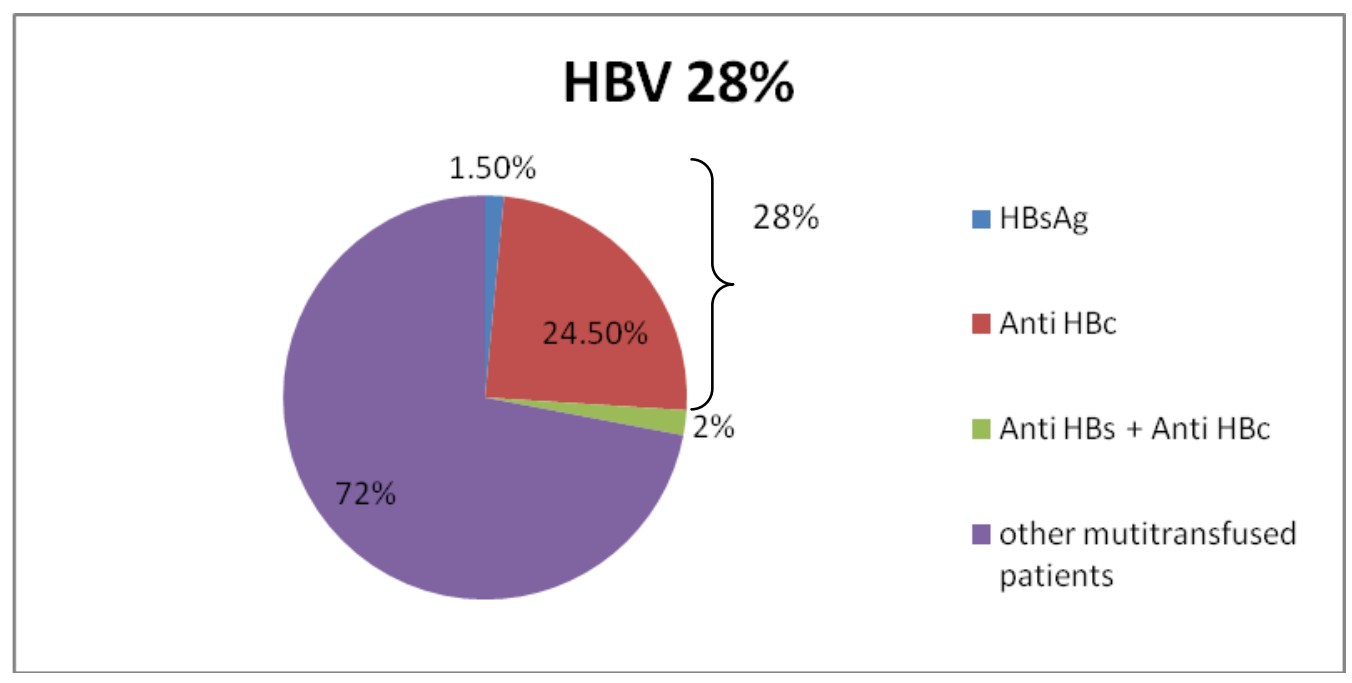


Fig.3 Vaccination \& HBV infection

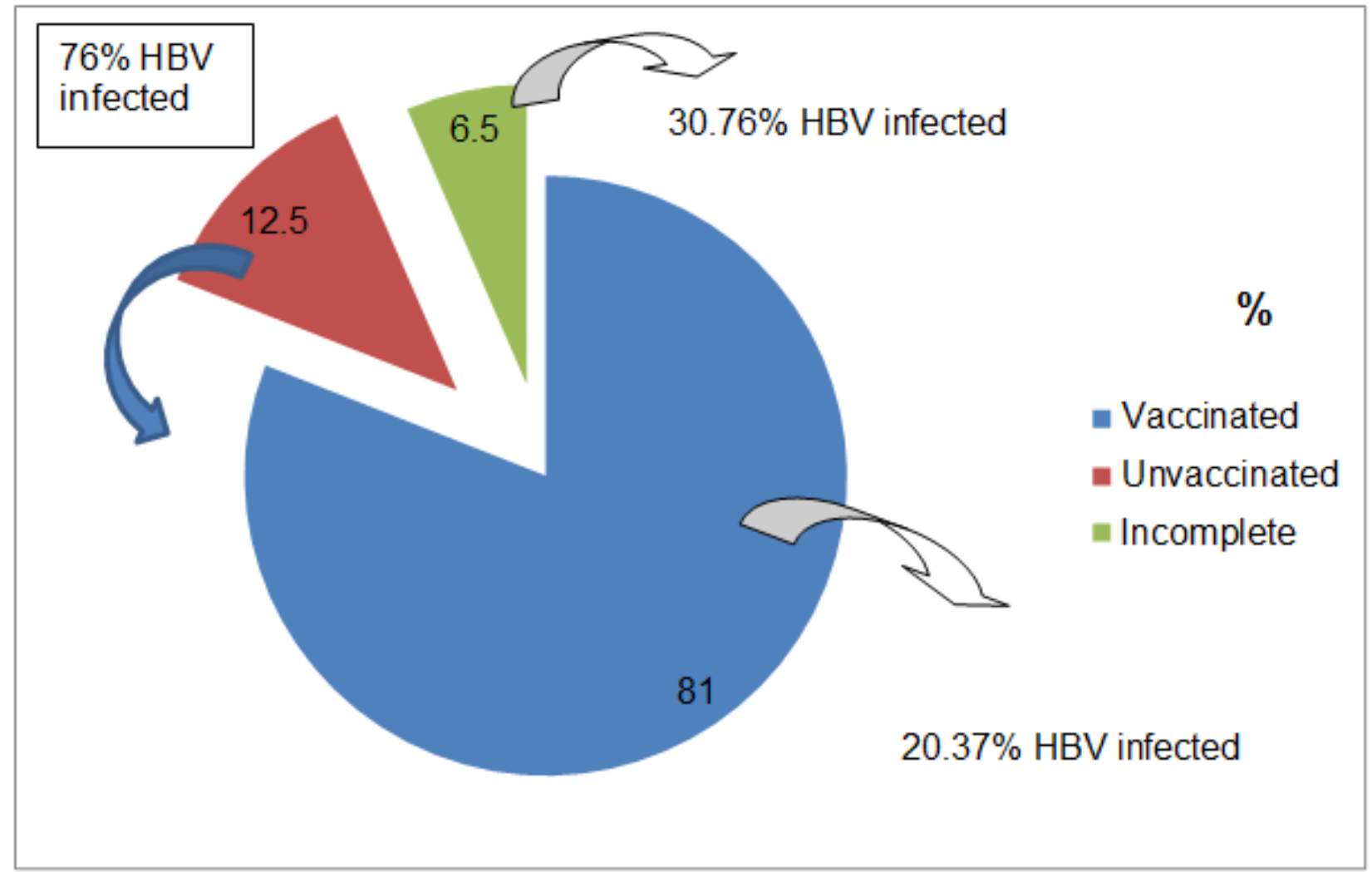

Fig.4 Vaccination \& Anti HBs titre

144 (88.88\%)With

protective Anti HBs titre

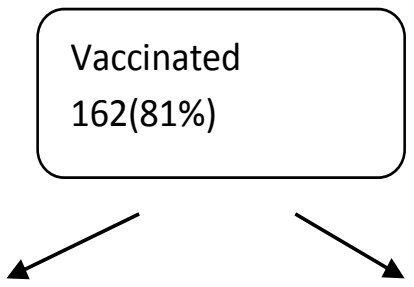

18 (11.11\%)Without protective Anti HBs titre

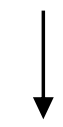

HBV infection

$5(27.7 \%)$ 
Fig.5 Occult HBV infection

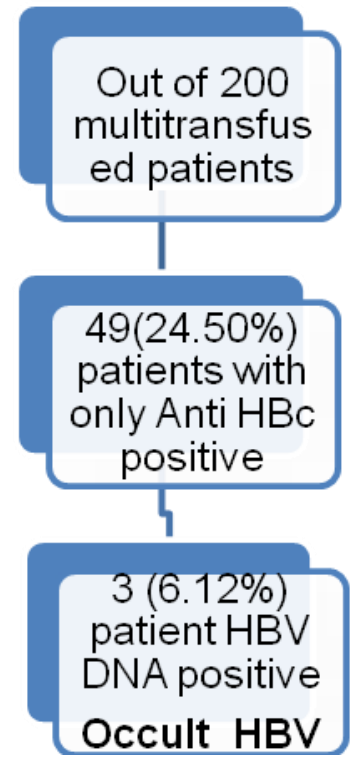

$18(11.11 \%)$ patients did not have detectable antibody titre level. This is could be explained by the fact that a certain percentage of those who receive vaccination are nonresponsive or hyporesponsive to the HBV vaccine. This particularly true for patients with chronic liver disease (26), renal disease or patients undergoing hemodialysis, as these patients lose HBV immunity after natural infection or vaccination. (3) Singh et al., (4)in their study in thalassemia have reported $24.28 \%$ of vaccine non responders.

One of the other reasons could be that these patients had a decrease in the antibody titre over a period of time. Mahoney et al.,(27) in their study have reported low antibody protective titres $(<10 \mathrm{IU} / \mathrm{ml})$ in nearly $60 \%$ of vaccinated patients 9 and 11 years post vaccination. (2)

This highlights the fact that mere vaccination is not sufficient but an antibody titre should be done after vaccination to find out whether the patient is protected. Also it should be repeated at regular intervals so that booster doses can be considered in low antibody titre patients.
In the present study, 30.76\% HBV infection was found in patients with incomplete vaccination (Fig. 3). This suggests that emphasis should be made on completing the vaccination schedule.

Earlier studies have shown that even HBsAg negative bloods may be anti-HBc/ HBV DNA positive and may retain the capacity to transmit infection. Hepatitis b core antibody has been reported to have the highest rate of association with occult infection (28).

So, in the present study, 49 Anti HBc positive samples without HBsAg, were tested for HBV DNA to find out the rate of occult infection which was found to be $6.12 \%$ (Fig. 5).

The gold standard for diagnosis of OBI is analysis of HBV-DNA extracts from the liver and blood samples. $(29,30,31)$

Occult blood infection (OBI) is defined as the presence of HBV DNA in the absence of HBsAg with or without the presence of Anti HBc. (32) Occult blood infection is recognised as a disease with important clinical implications including cirrhosis and 
hepatocellular carcinoma (33) Presence of occult HBV infection has also been reported from various parts of India (21)

OBI may be involved in many different clinical conditions that may be schematically summarized in four main contexts (34) it can be transmitted (through blood transfusion and organ mainly liver - transplantation), causing typical hepatitis B in newly infected individuals; b) the development of an immunosuppressive status (i.e., by immunetherapy) may induce OBI reactivation and development of acute and sometimes fulminant hepatitis; c) a large body of data suggests that OBI can contribute to the progression of the chronic liver disease toward cirrhosis and d) much evidence suggests that OBI can be involved in hepatocellular carcinoma (HCC) development.(33)

HBV is a well-known oncogenic virus and the main risk factor for $\mathrm{HCC}$ development.

In fact, there is evidence that OBI may favour or accelerate the HCC development in patients with chronic hepatitis of different etiologies including the $\mathrm{HCV}$ infection that appears to be a condition particularly prone to HCC development in case of concomitant OBI (33)

The HBV DNA detection rate is highest in subjects who are anti $\mathrm{HBc}$ positive but anti HBs negative and these individuals are more likely to be infectious. (35)

Urbani et al.,(36) illustrated that the serological assay for the long-lasting antibody response to the highly immunogenic HBV core antigen (anti-HBc) represents a qualified candidate as a surrogate for DNA amplification, or for increasing overall sensitivity when assessing the risk of occult hepatitis in peripheral blood.
The risk of occult hepatitis associated with anti-HBc seropositivity has been demonstrated extensively, and the presence of antibody response to $\mathrm{HBc}$ can be considered a sentinel marker of occult HBV infection. Recent studies have confirmed the existence of occult HBV infection in samples with anti$\mathrm{HBc}$ alone (35)

Sen S et al., (37) in their study in HIV and HBV coinfected population have reported a single case of OBI in patients with anti-HBc total antibodies.

Similar low positivity of $0-1 \%$ for $\mathrm{HBV}$ DNA-PCR in individuals with anti-HBc alone status has been reported in both immunocompromised as well as immunocompetent populations.

In the present study, out of 49 Anti $\mathrm{HBc}$ positive patients three patients were $\mathrm{HBV}$ DNA positive.

As OBI can be considered as a risk factor for hepatocellular carcinoma, fibrosis and Cirrhosis(38) screening of these multitransfused patients is needed. Also more studies should be carried out, especially in multi-transfused patients to know the exact burden of OBI.

To summarize, HBV infection continues to be a major problem in Multitransfused patients. Therefore, preventive measures, especially HBV vaccination to be given particularly thalassaemics and those suffering from HCV.

Although the blood products are screened for HBsAg, Hepatitis B infection remain a major problem in multi transfused patients. Robust vaccination program for hepatitis $B$ with emphasis on complete hepatitis B vaccination with regular follow up for anti $\mathrm{HBs}$ titre and providing booster doses for those in need should be implemented. Newer technologies 
such as HBV DNA PCR should be introduced in the routine screening of blood donors to reduce the window period and prevention of transfusion of the infected blood.

\section{References}

1. Mirmomen S, Alavian SM, Hajarizadeh B, Kafaee J, Yektaparast B, Zahedi MJ, et al., Epidemiology of hepatitis B, hepatitis $\mathrm{C}$, and human immunodeficiency virus infecions in patients with beta-thalassemia in Iran: a multicenter study. Arch Iran Med. 2006; 9(4): 319-23.

2. Laguna-Torres $\mathrm{V}$ a, Pérez-Bao J, Chauca G, Sovero M, Blichtein D, Chunga a, et al., Epidemiology of transfusion-transmitted infections among multi-transfused patients in seven hospitals in Peru. J Clin Virol. 2005; 34(2): S61-8.

3. Tsouchnikas I, Dounousi E, Xanthopoulou K, Papakonstantinou S, Thomoglou V, Tsakiris D. Loss of hepatitis B immunity in hemodialysis patients acquired either naturally or after vaccination. Clin Nephrol. Germany; 2007; 68(4): 228-34.

4. Singh H, Pradhan M, Singh RL, Phadke S, Naik SR, Aggarwal R, et al., High frequency of hepatitis $\mathrm{B}$ virus infection in patients with beta-thalassemia receiving multiple transfusions. Vox Sang. 2003; 84(4): 292-9.

5. Chemin I, Trépo C. Clinical impact of occult HBV infections. J Clin Virol. 2005 Dec; 34 Suppl 1: S15-21

6. Shaker O, Ahmed A, Abdel Satar I, El Ahl H, Shousha W, Doss W. Occult hepatitis B in Egyptian thalassemic children. J Infect Dev Ctries. 2012 Apr 13; 6(4): 340-6.

7. Candotti D, Allain JP. Transfusiontransmitted hepatitis B virus infection. J Hepatol. 2009; 51(4): 798-809.
8. Raimondo G, Pollicino T, Cacciola I, Squadrito G. Occult hepatitis B virus infection. J Hepatol. 2007; 46(1): 16070.

9. Mollah AH, Nahar N, Siddique MA, Anwar KS, Hassan T, Azam MG. Common transfusion-transmitted infectious agents among thalassaemic children in Bangladesh. J Health Popul Nutr. 2003; 21(1): 67-71.

10. M Mittal, S Zaman, N Bhatnagar, M Gajjar. Transfusion Transmitted Infections In Patients With Hemophilia: A Study From A Tertiary Care Hospital In Western India. The Internet Journal of Infectious Diseases. 2013; 12 (1).

11. Sawke N, Sawke GK, Chawla S. Seroprevalence Of Common Transfusion - Transmitted infections among Blood Donors: People's J Sci Res. 2010; 3(1): 5-8.

12. Balgir RS. The burden of haemoglobinopathies in India and the challenges ahead. Curr Sci. 2000; 79(11): 1536-47.

13. Shah N, Mishra A, Chauhan D, Vora C, Shah NR. Study on effectiveness of transfusion program in thalassemia major patients receiving multiple blood transfusions at a transfusion centre in Western India. [Internet]. Asian journal of transfusion science. 2010. p. 94-8.

14. Sabat J, Dwibedi B, Dash L, Kar SK. Occult HBV infection in multi transfused thalassemia patients. Indian $\mathbf{J}$ Pediatr. 2015 Mar; 82(3): 240-4.

15. Bhavsar H, Patel K, Vegad M, Madan M, Pandey A. Prevalence of HIV, Hepatitis B and Hepatitis C infection in Thalassemia major patients in tertiary care hospital, Gujarat. Aids. 2008; (April): 47-50.

16. Soni P, Trivedi N, Shah P, Prevalence K, College BJM. A Prevalence Of HIV, HBV and HCV In Patients of Thalassemia. 2014; 28(2277): 299-301. 
17. Oza T, Agrawat A, Dhruva G, Oza H V. A Study Of Prevalence Of HIV, HbsAg And HCV In Thalassemia Major Children. 2012; 114-7.

18. Sharma DC, Rai S, Bharat S, Iyenger S, Gupta S. A 10 Years Comparative Study to Assess Trends in Seroprevalence of Transfusion Transmitted Infections among Blood Donors at Gwalior, India. 2014; (June): 24-32.

19. Puri P. Tackling the Hepatitis B Disease Burden\&nbsp; in India. J Clin Exp Hepatol. Elsevier Ltd; 2014; 4(4): 3129.

20. Datta S. An overview of molecular epidemiology of hepatitis B virus (HBV) in India. Virol J. 2008; 5(1): 156.

21. Dr Kusumita Mandal1 DSKRKM. Seroprevalence of Transfusion Transmitted Infection (TTI) among Healthy Blood Donor and Their Distribution within Blood Groups - A Study from JMSCR January. 2015; 3(1): 3799-805.

22. Schreiber GB, Busch MP, Kleinman SH, Korelitz JJ. The Risk of Transfusion-Transmitted Viral Infections. N Engl J Med. 1996; 334(26): 1685-90.

23. Allain JP, Stramer SL, Carneiro-Proietti ABF, Martins ML, da Silva SNL, Ribeiro M, et al., Transfusiontransmitted infectious diseases. Biologicals. Elsevier Ltd; 2009; 37(2): 71-7.

24. El-Zayadi A-R, Ibrahim EH, Badran HM, Saeid A, Moneib NA, Shemis MA, et al., Anti-HBc screening in Egyptian blood donors reduces the risk of hepatitis B virus transmission. Transfus Med. England; 2008 Feb; 18(1): 55-61.

25. Coleman PF. Detecting Hepatitis B Surface Antigen Mutants. 2006; 12(2).

26. Van Thiel DH, Gavaler JS. Response to
HBV vaccination in patients with severe liver disease. Absence of an HLA effect. Dig Dis Sci. United States; 1992 Sep; 37(9): 1447-51.

27. Mahoney FJ. Update on diagnosis, management, and prevention of hepatitis B virus infection. Clin Microbiol Rev. 1999; 12(2): 351-66.

28. Irshad M, Peter S. Spectrum of viral hepatitis in thalassemic children receiving multiple blood transfusions. Indian J Gastroenterol. India; 2002; 21(5): 183-4.

29. Nishikawa H, Osaki Y. Clinical significance of occult hepatitis B infection in progression of liver disease and carcinogenesis. J Cancer. 2013; 4(6): 473-80.

30. Samal J, Kandpal M, Vivekanandan P. Molecular Mechanisms Underlying Occult Hepatitis B Virus Infection. Clin Microbiol Rev. 2012; 25(1): 142-63.

31. Lai C-L, Yuen M-F. Prevention of hepatitis B virus-related hepatocellular carcinoma with antiviral therapy. Hepatology. United States; 2013 Jan; 57(1): 399-408.

32. Biswas A, Panigrahi R, Chandra PK, Banerjee A, Datta S, Pal M, et al., Characterization of the occult hepatitis $B$ virus variants circulating among the blood donors from eastern India. ScientificWorldJournal. 2013; 2013: 212704.

33. Hu K-Q. Occult hepatitis B virus infection and its clinical implications. J Viral Hepat. England; 2002 Jul; 9(4): 243-57.

34. Squadrito G, Spinella R, Raimondo G. The clinical significance of occult HBV infection. Ann Gastroenterol. 2014; 27(1): 15-9.

35. Said ZNA. An overview of occult hepatitis B virus infection. World J Gastroenterol. 2011; 17(15): 1927.

36. Urbani S, Fagnoni F, Missale G, 
Franchini M. The role of anti-core antibody response in the detection of occult hepatitis B virus infection. Clin Chem Lab Med. 2010; 48(1): 23-9.

37. Sen S, Panda SP, Shanmuganandan K, Gupta R, Praharaj A. Prevalence of occult hepatitis B amongst Indian human immunodeficiency virus type 1 infected individuals-a pilot study. Med J
Armed Forces India. Director General, Armed Forces Medical Services; 2012; 68(1): 16-9.

38. Arababadi MK, Ahmadabadi BN, Daredor HY, Kennedy D. Epidemiology of occult hepatitis B infection among thalassemic, hemophilia, and hemodialysis patients. Hepat Mon. 2012; 12(5): 315-9.

\section{How to cite this article:}

Paranjpe Supriya, M., S. Supare Sundaram, Nataraj Gita and Mehta Preeti, R. 2019. Seroprevalence of Hepatitis B Virus in Multitransfused Patients with Special Reference to Occult Hepatitis B Virus Infection. Int.J.Curr.Microbiol.App.Sci. 8(07): 2446-2456. doi: https://doi.org/10.20546/ijcmas.2019.807.301 